\title{
Circular Economy, resources and environmental metabolism
}

ISSN 1857-9973 UDC 338.121:658.567(100)

\section{Riste Temjanovski, ${ }^{1}$ Zlatko Bezovski, ${ }^{2}$ Monika Arsova ${ }^{3}$ Elenica Sofijanova ${ }^{4}$}

1 University Goce Delcev Stip, Faculty of Economics, riste.temjanovski@ugd.edu.mk

2University Goce Delcev Stip, Faculty of Economics, zlatko.bezovski@ugd.edu.mk

3 University Goce Delcev Stip, Faculty of Economics, monika.arsova@ugd.edu.mk

4 University Goce Delcev Stip, Faculty of Economics, elenica.sofijanova@ugd.edu.mk

\begin{abstract}
Resource allocation is increasing as an global issue, because resources (natural resources, ores, oil resources) are in limited quantities worldwide, as opposed to everincreasing human needs. Therefore, resource allocation is the deployment and optimal utilization of a defined resource. In the economic arena, allocation is usually controlled by the pricing mechanism: if the demand for a resource is high, then the cost of the resources used will be high; due to such high prices, this resource will be used for limited needs. When the price of natural resources and materials rises, in response to volatile markets and increased competition, developed nations are looking at possible alternatives as a promising economic model. In that regard, the circular economy is considered as an expected solution.
\end{abstract}

As one of the objectives of the circular economy is the need of resources, improving resource efficiency or the need for resource efficiency targets remains equally relevant for circular economy policies. The challenges in the circular economy are long-standing and crucial in tackling resource depletion and the new environmental problems facing humanity.

The fundamental and comprehensive structural changes are in the complete redesign of the existing linear economic system and the acceptance and comprehensive inclusion of the circular economy as a new economic hope. A circular economy is one in which products are recycled, repaired or reused rather than thrown away, and in which waste from one process becomes an input into other processes.

Based on the general concern that the world is entering an intensified period of resource stress, a commitment to urgent behavioral research to identify the most important natural resource trends affecting the human environment is more than necessary. The identified trends - which will include patterns of demand, supply, availability, price levels, and price volatility - are shaped and influenced by emerging climate changes, evolving demographic patterns, increasing economic development, and human induced environmental degradation. 
Keywords: resources, environment, circular economy, policymakers,

\section{Introduction}

The situation with today's modern global trends, the process of industrialization, rising living standards and adverse impacts of such reversion processes expressed by uncontrolled and disproportionate use of natural resources to alert humanity of all levels of institutionalization: personal, national, regional and global.

According to Stahel's [1] review in The Performance Economy, in today's Industrial Economy, a higher throughput (resource consumption) means economic growth and an increased Gross National Product (GNP) as well as higher corporate revenues and more jobs. But the reverse is also true: the high standard of living in industrialised countries is based on high annual resource consumption, which has led to 20 per cent of the world population consuming 80 per cent of all resources. Furthermore, it underlines the importance and the shift to the Performance Economy as well as emphasizes changes in the role of the resources: the goods of today are the resources of tomorrow at yesterday's prices.

The increasing demand and limited supply of resources, of which some critical substances are becoming scarce already, confronts society with the risks of dependency, shortage and increased cost. This causes a major challenge in several ways. Additional sourcing of resources will most likely cause more severe negative impact on the environment. New, less attractive and less accessible locations for sourcing/mining will be explored, causing land degradation, deterioration and local damage, while being more costly due to the location and the increase in social and environmental pressure on mining.[2]

According to OECD study [3], natural resources, both renewable and non-renewable, and ecosystem services are a part of the real wealth of nations. They are the natural capital out of which other forms of capital are made. They contribute towards fiscal revenue, income, and poverty reduction. Sectors related to natural resources use provide jobs and are often the basis of livelihoods in all communities. Owing to this fundamental importance of natural resources, they must be managed sustainably. Government plays the essential role in putting into place policies that ensure that resources contribute to the long-term economic development of nations, and not only to short-term revenue generation. High-quality institutions in the present, and planning for the future, can turn the socalled - resource curse into an opportunity.

The global economic system, which is expanding through the breath of modern technology, has formed a wide field of action: multinational companies, significant power in the use of natural resources and a widening gap between them and developing countries. As a result, the world economy is more vulnerable to shocks today than in previous decades. The imperative for successfully dealing with all global challenges is to be first, to be the greatest, in step with the dynamic developments in the international environment. But how to maintain all this global growth, and to preserve the natural resources that are mostly used in such international and intercompany competitions.

The world economy is experiencing a boom with the constant transformation and combination of technological and geopolitical forces. This combination has made it possible to create the globalization of culture, the globalization of the economy and the globalization of the environment. The fact is that the global economic order is approaching the limits of what can be considered sustainable and is becoming increasingly difficult to ignore. The need for a sustainable model 
becomes imperative for all human development. Increased global demand from a growing and affluent population opposes resource constraints, environmental degradation, and climate change. Or in the best case, are we unknowing prisoners of our own conceptions about global sustainable society? In these lines of thought, a green circular society requires societal movement from a linear philosophy of traditional industrial processes raw materials, products, wastes to a novel circular economy model in industrial sector. [4]

In such a dynamic environment as a possible way out to overcome the existing problems, the focus of attention directed towards the circular economy. In a traditional economy, everything is direct, from support to grave: extraction, creation and transfer. In the roundabout economy, utilization designs are intended to reflect the patterned approach of regular biological communities. Once utilized, all merchandise give results that can be reused in other assembling forms, making a righteous cycle more tuned in to the earth. The Circular Economy utilizes waste to create new assets and add to a roundabout economy. [5]

Circular economics promotes the concept of a complex and sustainable ecosystem, where efficiency is promoted through re-use, repair, or remanufacturing practices. Social and environmental metabolism, especially from an industrial point of view, provides a useful lens in studying the circular economy as it relates to both resource use and the carrying capacity of the global environment. This acts as an important basis to look at closed loops between inputs and outputs. On this point, Baars [6] suggests that life cycle thinking offers a suitable approach in assessing the impact of products beyond the traditional production site. It involves the environmental impact and potential economic gains associated at all stages of a product's lifecycle, including material extraction, manufacture, distribution, consumption, and end-of-life.

\section{Resources and How to Be More Productive With Limited Resources}

According to The National Intelligence Council [7] the demand for resources is likely to continue to grow in the coming decades. Energy demand is set to grow by 50 percent by 2030 according to the International Energy Agency. According to the United Nations Environment Program (UNEP), the amount of minerals, ores, fossil fuels, and biomass consumed globally per year could triple between today and 2050. Global growth in water demand for all uses is also set to increase by 50 percent over the same period compared with current consumption. Intensified resource stresses will bring new risks and uncertainties to international relations in an already turbulent world.

As the biggest threats to environmental degradation, reduction of reserves of significant natural resources, in addition to intensive urbanization processes around the world and as well as shifting global economic power, as limiting and unfavorable factors are mentioned:

- Resource consumption patterns are driven by a range of factors: demographics and economic development are increasing demand, technology influences costs and the nature of both supply and demand, while environmental and social pressures increase the burden on both producer and consumer countries.

- No one knows whether today's domestic and transnational institutions, market systems, and multinational arrangements will be able to cope with these rising resource stresses.

- Distortive subsidies and a failure to price in other, indirect social costs increase complexity. A further layer of interconnection among resources emanates from their joint dependence on stable transportation infrastructure.

Inequality in access to and use of natural resources is driving both global poverty and environmental destruction. Reducing this inequality must therefore be central to all development efforts worldwide. The conventional consumption pattern of people in wealthy countries - and the 
middle classes of the developing world - is driving the vast majority of natural resource degradation. The wealthiest 20 per cent of the world's population account for 80 per cent of consumption of global resources. And we are currently using 50 per cent more natural resources than the earth can sustain, with devastating impacts on nature and on how people access food, fresh water, land and energy.[8]

According to Lacy Peter and all [9] companies no longer focus mainly on driving more volume and squeezing out cost through greater efficiency in supply chains, factories and operations. Rather, they concentrate on rethinking products and services from the bottom up to "future proof" their operations to prepare for inevitable resource constraints - all the way through to the customer value proposition. This implies eliminating waste, creating step changes in resource productivity and at the same time enhancing the customer value proposition on dimensions such as price, quality and availability.

The potential of a national economy or company consists of its resources, which enable it more or less competence and competitiveness in the market. The fact is that if the resources are managed properly, ie if a system of resource management is established, then good potentials for economic operations are created.

The main question in our research is what are resources and how to cope with deficiency of them? Resources refer to anything that can contribute to economic activity. There are two basic categories of resources: natural [10] or inhuman and human resources. In the initial stages of development, natural resources, along with physical labor, were a crucial development factor navigable rivers, access to the sea, fertile agricultural land, hunting opportunities, etc., but with the development of the economy and knowledge, their relative importance decreased, and the importance of other factors has increased.

In the classification of natural resources there is an additional division of exhaustive sources into: renewable and non-renewable. The first category includes living resources (plants, animals, etc.) due to their regenerative power. The latter are considered non-renewable and include soil, minerals or fuels, which after use are not regenerated or take millions of years to recover. Nonrenewable resources are resources that either exist in fixed supply or are renewable only on a geological timescale, whose regenerative capacity can be assumed to be zero for all practical purposes. Examples of these resources include metallic minerals like iron, aluminum, copper and uranium; and nonmetallic minerals like fossil fuels, clay, sand, salt and phosphates. Nonrenewable resources can be classified into two broad categories. The first group includes those resources which are recyclable, such as metallic minerals. The second group consists of nonrecyclable resources, such as fossil fuels.[11] They are defined in the development process with a high degree of scarcity, although they are mostly "guilty" of the constant search for alternative sources and their substitution which in the long run leads to the development of new materials, products, surrogates and substitutes of existing natural resources and new energy sources from sustainable or renewable natural resources.

In economics there are different views on the impact of natural resources on economic development. The quantity, quality and distribution of natural resources is an important factor in dimensioning the economic development of a country. The orientation of the economy to use its own raw material base and the benefits provided by natural resources, greatly reduces the economy's dependence on the external market.

But there are also negative views on the importance of natural resources for economic development. But in development theory, such an approach is often the subject of serious criticism and inconsistencies. Excessive use of land and natural resources, without proper care or at the expense of other development factors, has so far proved to be a kind of "trap" in which economies end up with high rates of natural resource exports relative to total exports. low economic growth and low income. 
New sustainable models require inevitable changes in the basic economic models of the term progress. Namely, the prospect of ever-extendable consumer desire, characterised as "progress", promised a new way forward for modern manufacture, a means to perpetuate economic growth. Progress required the endless replacement of old needs with new, old products with new. Notions of meeting everyone's needs with an adequate level of production did not feature. In this sense, the twentieth century capitalist era unleashed desire with its complex individual peculiarities and set it loose in the marketplace of material goods, supplanting basic survival needs as the purpose and driver of economic growth. Up to now, there has been little change in this strategy. As we run up against the limits of material production, nothing could be more inimical to finding solutions. [12] In that context, the need for each economy for the highest priority in resource allocation planning is imposed. Resource allocation is increasing as an issue because resources (natural resources, ores, oil resources) are in limited quantities worldwide, as opposed to ever-increasing human needs. Therefore, resource allocation is the deployment and optimal utilization of a defined resource. In the economic arena, allocation is usually controlled by the pricing mechanism: if the demand for a resource is high, then the cost of the resources used will be high; due to such high prices, this resource will be used for limited needs. When the price of natural resources and materials rises, in response to volatile markets and increased competition, developed nations are looking at possible alternatives as a promising economic model. In that regard, the circular economy is considered as an expected solution. The longer materials and resources are used, the more value is extracted from them. This can help reduce dependence on critical materials, but also reduce aggregate demand by restoring the resources, nutrients or energy contained in products at the end of their useful life.

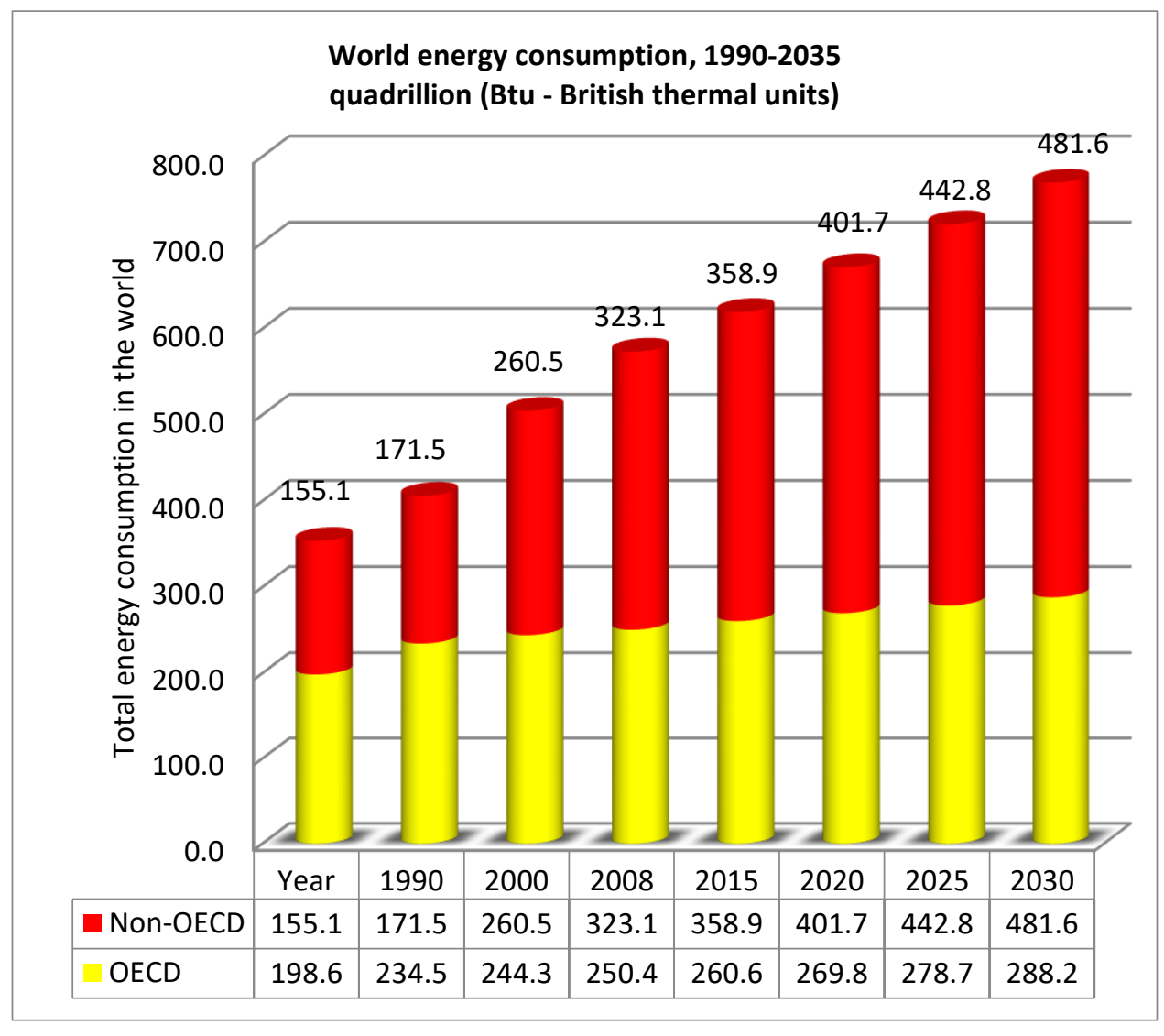

Figure 1 World energy consumption, 1990-2035 quadrillion (Btu - British thermal units) 
Source: U.S. Energy Information Administration | International Energy Outlook 2011

With resource efficiency and the circular economy being a relatively new and cross-cutting issue, there are comparatively few examples of ex post policy evaluations in these two areas. Potential aspects to consider include the benefits from the circular economy in terms of reduced resource use, greenhouse gas emissions, and water and land use.[13]

One of the future key challenging policies of the circular economy should be position-oriented perception of "waste as a problem" to "waste as a resource"'.[14] To this end high levels of cooperation are needed between the waste industry and enterprises engaged in circular economy business models. Collecting high quality waste streams for re-use, remanufacturing and recycling also requires citizen engagement and integrated infrastructure development from the municipal to the EU level.

\section{Circular economy and new human expectation}

In nature, there is a cycle of nutrients constantly flowing - from the soil to plants to animals and back to the soil - that allows the entire ecosystem to flourish. Plants need nutrients such as phosphorous and nitrogen to grow. These plants and the animals that eat them will eventually decompose, returning these nutrients back into the soil. Natural systems therefore are an example of circularity in action.[15]

Today's existing principles of Economics are based on the so-called line model which means it starts with the extraction of the raw material, and then goes through the process of converting these materials into products and finally puts these products on the market to reach the final consumers. After use by consumers, these products end up in the trash, because almost all the products we use, after a while we will decide that they are garbage and we will get rid of them. All these products, having in mind also the process of their creation contribute to have all the environmental problems that we have today, but not only that, which represent increased costs.

As one of the objectives of the circular economy is the need of improving resource efficiency, or the need for resource efficiency targets remains equally relevant for circular economy policies. The challenges in the circular economy are long-standing and crucial in tackling resource depletion and the new environmental problems facing humanity. The complex nature of material and energy systems and changing economic and technological conditions depend on a humane approach to nature, on resources and, of course, on regional policies and measures taken in developed countries, emerging countries and the least developed countries in the world.

Circular economics as an alternative model focuses on separating growth from underutilization of resources - provides the key to managing this challenge at both macro and micro levels, enabling economic development within the limits of natural resources, and enabling companies to innovate to enable customers and users to do "more with less". The circular economic model is basically a complex system that with its mechanisms replaces the classic, one-way concept of the life cycle, offering a new systemic order to the so-called redesign of material flows, enabling the use of renewable energy sources. Its main goal is to get rid of waste through a circular design of material processing, use of the products themselves and system applications, introducing efficient business models in the permanent or long-term utilization of their resources.

A circular economy is an industrial system that is restorative or regenerative by intention and design. The economic benefit of transitioning to this new business model is estimated to be worth more than one trillion dollars in material savings. According to the same report of Ellen MacArthur 
[16], some 65 billion tonnes of raw materials entered the economic system in 2010, and this figure is expected to grow to around 82 billion tonnes in 2020.

The circular economy goes further than calling for implementation of 'sustainable', 'green', resource-effective and environment-friendly technologies in isolated links of production systems. It requires a broader and more comprehensive design of radically alternative solutions over the entire life cycle of products and adoption of closing-the-loop production and consumption patterns within the entire economic system. The circular economy relies on value creation through restoration, regeneration and re-use of resources, enabled by new types of business models and forms of consumption that discard ownership and rely on active 'users' rather than passive "consumers". [17] In such circumstances, the circular economic model introduces and develops an agenda for radical change, which involves and integrates the production and consumption sides of our societies.

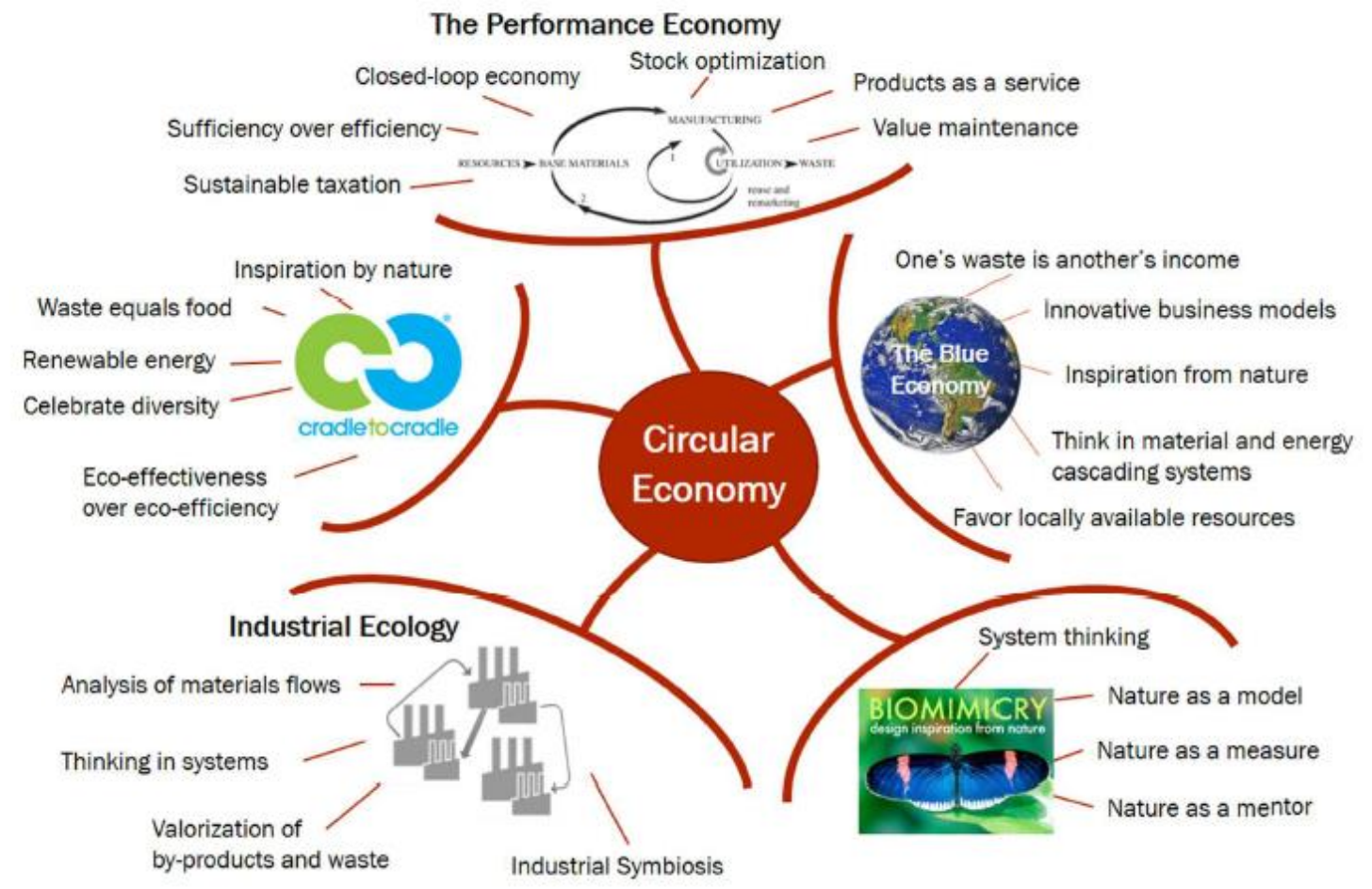

Figure 2 The Concept of Circular Economy: its Origins and its evolution

Source: Wautelet Thibaut: The Concept of Circular Economy: its Origins and its evolution. 2018 : https://www.researchgate.net/publication/322555840 [accessed 24.02.2021]

Processes in the systemic concept of circular economics cannot be reduced to simple and limited procedures for the reduction, reuse and recycling of raw materials or products. It was also Walter Stahel who pioneered the term "cradle to cradle" which expresses one of the key ideas of the circular economy, namely that everything that is born and lives can be born again and gain new life. But one of the predecessors of cycle-based thinking is Industrial Ecology (IE): ...In so doing, the now conventional cradle-to-grave approach to product design, development and analysis is replaced by a renewing cycle of Cradle-to-Cradle analysis, transforming the industrial capitalism model for linear thinking to a closed loop system. This thinking resonates with early principles put forward by proponents of Industrial Ecology and Natural Capitalism [18]. The most important aim of Industrial Ecology is to eliminate the concept of waste, in which waste is regarded as unusable 
and worthless materials. In nature nothing is thrown away, but all materials are re-used with great efficiency and effectiveness (Graedel, 1995). Graedel and Allenby propose the term industrial symbiosis, like as the organization of industrial organisms and their processes so that "the effluents of one process...serve as the raw material for another process".[19]

According to Cardoso [20] the aim is to produce goods that, when they reach the end of their useful life, are not turned into useless waste, but can instead be decomposed and turned into nutrients for plants and animals or used as raw material for the manufacture of new products in a new industrial cycle. The intention is that in the cities of the future the buildings that are constructed will produce more energy than they consume. It is no longer considered important to discuss the problem of the shortage of fossil fuel reserves, since such reserves are rendered obsolete through the increasing recourse to alternative energies. It is even admitted that the effluents produced by factories may enter into the distribution circuits of our drinking water.

In today's societal practices, important steps have been taken to introduce processes of reuse, repair and recycling, adding significant feedback loops to the linear production-consumption model. These loops are often approached as separate optimization steps. The concept of circularity, however, goes substantially further. First, it focuses on designing products in such a way that they can be easily repaired, disassembled for renewed use of components, or enable an easy recuperation of raw materials.[21]

The need of discussion about circular economy is increasingly gaining the support of business and enjoys increasing recognition in the European Commission: „Transition to a more circular economy requires changes throughout value chains, from product design to new business and market models, from new ways of turning waste into a resource to new modes of consumer behaviour. This implies full systemic change, and innovation not only in technologies, but also in organisation, society, finance methods and policies" [22].

The circular economy, therefore, is more than just recycling. It is an economic model that spans supply chains and sectors, and redefines the process of product design, manufacturing and consumption, thus opening up new, unexploited (secondary) markets for companies. We are not setting out to decide whether the circular economy is a passing fad, a utopian ideal or a new economic paradigm, but we do see that the idea of the circular economy, waste reduction and the more efficient use of resources, as a trend, is gaining more and more traction globally. [23]

\section{How societies can be win in circular economy battlefield environment}

The benefits of cycling in manufacturing processes have been known for a long time ago. Swiss architect and industrial analyst Walter Stahel, the man who first sketched the Performance Economy concept, noted the many benefits. The results showed that on a macro-economic level, three quarters of energy is used in mining activities and basic material production, while one quarter is used in manufacturing goods from basic material. Reversed proportions were found for manpower. In that regard, product-life extension constitutes the best strategy to substitute manpower for energy as these activities are the most labor intensive in comparison to manufacturing ones. Accordingly, Stahel and Reday-Mulvey (1981) argued that an economy with closed loops favoring reuse, repair and remanufacturing of goods over manufacturing of new goods has positive impact in terms of job creation, economic competitiveness, resource savings and waste prevention. This report is recognized as the first to articulate the idea of a circular economy, which was further elaborated later in Stahel's book "The Performance Economy". In his book, Stahel presents the Performance Economy as a set of strategies to overcome the shortcomings of the present industrial economy which is characterized by a combination of 
continuously high resource consumption with related high waste volumes, rising public debt often accompanied by persistent unemployment and slow economic growth. [24]

According to Stahel [25], the main moto in the Performance Economy is also changes the role of resources: the goods of today are the resources of tomorrow at yesterday's prices. A Performance Economy calls for a shift in economic thinking from "doing things right" to "doing the right things". "Doing things right" refers to approaches focusing on solving problems (e.g. waste generation, toxic substances) with the aim to reduce the environmental impact. Furthermore, Stahel underlines the three main goals of the Performance Economy - exploiting science, creating jobs at home and exploiting the opportunities of an extended performance responsibility - can be pursued independently. Economic actors thriving to achieve all three goals in a coordinated way, however, will reap substantial synergetic benefits.

Further numerous analyzes made in many sectors and activities clearly indicate the financial and non-financial benefits from the implementation of the circular economy. Such views are noted in analyzing prepared by Ellen Macarthur foundation where the economies will expected to benefit from substantial net material savings, mitigation of volatility and supply risks, positive multipliers, potential employment benefits, reduced externalities, and long-term resilience of the economy. Based on detailed product level modelling, the report estimates that the circular economy represents a net material cost saving opportunity of USD 340 to 380 billion p.a. at EU level for a "transition scenario" and USD 520 to 630 billion p.a. for an "advanced scenario", in both cases net of the materials used in reverse-cycle activities. Benefits in the advanced scenario are highest in the automotive sector (USD 170 to 200 billion p.a.), followed by machinery and equipment (USD 110 to 130 billion p.a.), and by electrical machinery (USD 75 to 90 billion p.a.). These numbers are indicative as they only cover "sweet spot" sectors that represent a little less than half of GDP contribution of EU manufacturing sectors. They also assume the addition of only one product cycle with today's technologies. Yet many cycles would be possible and technological innovation could likely lead to rapid improvements and additional cost savings.

The other benefit of "migration" to circular economy is new job creation. The transition to more circular systems of production and consumption will inevitably impact both the numbers of people employed in the sector - and their skill sets. "Repair" activities account for nearly half of all people employed in the circular economy, in particular as they are labour intensive. Indeed, thousands of social enterprises across Europe have been active in the repair sector for many years, providing job and training opportunities for disadvantaged workers and giving them a fresh start on the labour market. Certain data indicate the unfavorable situation of the repair sector, where that are in decline, in particular due to increasing obstacles and costs to re-use and repair. This trend should be reversed. Overall, it is estimated that the implementation of existing legislation on waste prevention and management could create more than 400000 new jobs. To avert skill bottlenecks that may delay the development of new value chains or the deployment of new technologies, it is essential to strengthen education and training that focus on short and long run strategies.[26] Humanity must take decisive steps towards the implementation of the model of circular economy. The circular economy is an "instrument" for achieving the goals of sustainable development and implies long-term investment in raw materials and energy efficiency, while reducing harmful emissions, replacing fossil fuels with renewable sources and production and trade in sustainable products, thus closing the circle "product - waste - product".[27] 


\section{EU policy and action to promote new, efficient business models}

The world is changing quickly, as yesterday's stability is rapidly replaced by today's international uncertainties. More than ever, the world needs a strong, self-confident and united Europe to maintain its position as an industrial leader and a driver of stability and prosperity. To meet the challenges Europe faces, technical solutions are required, but will not go far enough on their own: even more importantly, Europe must embrace new ways of thinking, re-define its core values and adapt its mindset. Because the way in which challenges are approached - the attitude taken when evaluating those that are most difficult, and whether consensus can be established across European society in how they are viewed - will determine whether a stable, prosperous future can be secured.[28]

Numerous estimations [29] show that our current economy is only $8.6 \%$ circular, leaving a massive Circularity Gap. The good news is that we only need to close the Gap by a further $8.4 \%-$ or roughly double the current global figure of $8.6 \%$-to get there. However, circularity in our $8.6 \%$ world is trending down, not up. Whilst the Circularity Gap Report 2020 revealed that the global economy was only $8.6 \%$ circular, just two years earlier it was $9.1 \%$-things have got worse.

Undoubtedly, there is an urgent need for the long-term sustainable development of humanity. This concept must focus on the need for a long-term friendly approach to maintaining a circular resource life. All countries in the world should provide appropriate framework conditions that will allow traditional business sectors to make full use of the potential for resource efficiency in production processes, product design and end-of-life management and to compete in new markets. Only by setting the principles of new, efficient business models will it be possible to prevent further devastation processes in nature, especially with natural resources. In this regard, public authorities should lead by example, take more account of environmental criteria and move from technological specifications to performance-based public procurement contracts, where they enable the improvement of efficiency and quality of life.

The developed world is undertaking various long-term project planning policies to deal with this problem. For example, the European Platform for Resource Efficiency calls on business, labor and civil society leaders to support resource efficiency and transformation into a circular economy and society now as this offers a way out of the current crisis towards re-industrialization of the European economy based on efficient growth. of resources that will last. A circular, efficient and resilient economy should be achieved in a socially inclusive and responsible way by:[30]

1. Encouraging innovation and accelerating public and private investment in resource-efficient technologies, systems and skills, also in SMEs, through a dynamic and predictable political, economic and regulatory framework, a supportive financial system and sustainable growth enhancing resource-efficient priorities in public expenditure and procurement.

2. Implementing, using and adopting smart regulation, standards and codes of conduct that cope: a) create a level playing-field, b) reward front-runners and c) accelerate the transition, and d) take into account the social and international implications of our actions.

3. Abolishing environmentally harmful subsidies and tax-breaks that waste public money on obsolete practices, taking care to address affordability for people whose incomes are hardestpressed. Shifting the tax burden away from jobs to encourage resource-efficiency, and using taxes and charges to stimulate innovation and development of a job-rich, socially cohesive, resource-efficient and climate-resilient economy.

4. Creating better market conditions for products and services that have lower impacts across their lifecycles, and that are durable, repairable and recyclable, progressively taking the worst performing products off the market; inspiring sustainable life-styles by informing and incentivising 
consumers, using the latest insights into behavioral economics and information technology, and encouraging sustainable sourcing, new business models and the use of waste as raw materials.

5. Integrating current and future resource scarcities and vulnerabilities more coherently into wider policy areas, at national, European and global level, such as in the fields of transport, food, water and construction.

6. Providing clear signals to all economic actors by adopting policy goals to achieve a resourceefficient economy and society by 2020 , setting targets that give a clear direction and indicators to measure progress relating to the use of land, material, water and greenhouse gas emissions, as well as biodiversity.

Table 1 Implications of resource models for natural resource management [31]

\begin{tabular}{|c|c|}
\hline Model & Implication for the EU \\
\hline Weak sustainability & $\begin{array}{l}\text { - Encourage savings } \\
\text { - Invest in human capital (education) } \\
\text { - Stimulate technology (accelerated depreciation etc.) } \\
\text { - Encourage economy-resource decoupling by } \\
\qquad \text { market based approaches; } \\
\text { - Population policies in LDCs } \\
\text { - Cost benefit appraisal } \\
\text { - Modified national product accounts } \\
\text { - Invest 'resource rents' }\end{array}$ \\
\hline Strong sustainability & $\begin{array}{l}\text { As for weak sustainability but } \\
\text { - More emphasis on quantity-based controls } \\
\text { - Indices of natural capital } \\
\text { - Less emphasis on cost-benefit but need to develop } \\
\text { notion of acceptable cost }\end{array}$ \\
\hline Materials intensity & $\begin{array}{l}\text { - Awareness raising } \\
\text { - Encourage resource efficiency }\end{array}$ \\
\hline Ecological footprints & $\begin{array}{l}\text { - Awareness raising } \\
\text { - Encourage resource efficiency }\end{array}$ \\
\hline Environmental space & $\begin{array}{l}\text { - Awareness raising } \\
\text {. Encourage resource efficiency }\end{array}$ \\
\hline Equity & $\begin{array}{l}\text { - Integrate with cost-benefit } \\
\text {. Ensure efficiency goal is honoured }\end{array}$ \\
\hline
\end{tabular}

Source: Pearce D.W. 2000. Public Policy and Natural Resource Management: A Framework for Integrating Concepts and Methodologies for Policy Evaluation, Report to DGXI, European Commission, Brussels. p.33.

Numerous studies and estimates show that over $90 \%$ of the raw materials used globally are not cycled back into the economy, resulting in massive overexploitation of the finite natural resources of our planet and burdening our climate. The Earth Overshoot Day, a yearly indicator of the overexploitation of the planet's biocapacity, is advancing every year. [32] With those radical and prosperous measures, EU will need a systemic change in the use and recovery of resources in order to improve the resilience of our environment, societies and economies, within the 
boundaries of the planet. This should boost competitiveness and contribute to a sustainable, reindustrialised European economy. According to a recent estimate, the EU could realistically reduce the total material requirements of its economy by $17 \%$ to $24 \%$, boosting GDP and creating between 1.4 and 2.8 million jobs. Similarly, the government of China launched the programme named the China Association of Circular Economy (CACE) - which includes government officials, academicians and entrepreneurs - to promote the growth of circular economy in that country. CACE data showed that the gross output value of the circular economy had grown by 15 percent on average from 2006 to 2010 in China, outpacing the nation's general economic growth by 4 percentage points. The CACE expects that the industry's output will further expand to 1.8 trillion yuan ( $\$ 293.43$ billion) by 2015 , from one trillion yuan in 2010 . Representatives of senior Chinese government policy, on the issue of the circular economy, advocate that "the circular economy has great potentials and the development of it will boost the recycling of resources and sustainable economic growth."[33]

The benefits of maximizing results in the field of circular economy are really impressive. According to the report published from Ellen MacArthur Foundation (EMF) and McKinsey Company [34] the potential benefits of the transition to a circular economy: The collaborative waves across four to five materials flows has potential to trigger net benefits of at least $\$ 500$ million and 100,000 new jobs, as well as to avoid/valorize 100 million tonnes of materials waste within 5 years. Fogarassy and Finger [35] suggest that the first principle of the circular economic concept is to keep resources under control and to balance the material flow of renewable energy sources, to preserve and increase natural resource systems. In the case of inputs, the system is basically used to maintain the flow of renewable energy sources, so-called "flow or flow management", and aims to continuously circulate stocks instead of accumulating them, i.e., to stockpile them, while serving technological processes. Therefore, in terms of economic processes, they also focus on ensuring that renewable materials, resources and non-renewable raw materials are always available. Another positive step ahead to better environmental is concept to green economy in EU perspectives. The EU considers that Rio+20 can mark "the start of an accelerated and profound, world-wide transition towards a green economy - an economy that generates growth, creates jobs and eradicates poverty by investing in and preserving the natural capital offers upon which the long-term survival of our planet depends. It can also launch the needed reform of international sustainable development governance". [36]

And yet, structural change is indispensable. Humanities has growing optimism about the potential of the "circular economy" as well as a new or advanced model for sustainable growth. However, to hijack Margaret Thatcher's famous expression, "there is no alternative". We need a different kind of economy, one designed to meet needs rather than create them; we need to abandon the consumer path to human advancement and the reduction of our choices to monetary terms. The consumer template for the human future has outworn its usefulness. Stimulating consumption in the interests of growth and chasing economies of scale was, perhaps, suitable for the "empty world". In the "full world" (and getting fuller) we need redistributive justice within and between countries and a plan for the rich world to reduce its material demands to allow space for the rest of the world to reach material security. [37]

The circular economy therefore remains highly relevant to keep in the sights as new sources of growth and economic renewal are considered. Achieving such a recovery will require the rethinking, resetting, and redesigning of the economy from one that is merely reactive in a time of crisis to one that is prosperous, inclusive, low-carbon, and mitigates the risk of future crises.[38] 


\section{Conclusion}

The fundamental and comprehensive structural changes are in the complete redesign of the existing linear economic system and the acceptance and comprehensive inclusion of the circular economy as a new economic hope. A circular economy is one in which products are recycled, repaired or reused rather than thrown away, and in which waste from one process becomes an input into other processes. Reuse means that the product produced by the producer should not be disposable, but it can be used repeatedly in order to save resource consumption and protect the ecological environment. The process of recycle is the core requirement of the circular economy. The waste generated in the production process can also be returned to the production process or by a chemical reaction conversion for other materials and make use of them.

The circular economy may best be realized at the city level where cities and their metropolitan regions are at just the right scale to make the shift. Only rational humanitarian action and behavior, the use of natural resources but also taking care of the balance and planned exploitation of resources on our planet, can stimulate scientific awareness to solve the problems that the process of globalization is continuously accumulating. In that context, the planned connection and the actions to switch to circular economy will become more and more important. Special importance for the circular economy as a modern scientific trend should be sought in the way humanity can and should progress further. What interest will dominate at a given moment is largely decided by the consciousness of the individual, the collective social consciousness and the public opinion.

The fundamental and comprehensive structural changes are in the complete redesign of the existing linear economic system and the acceptance and comprehensive inclusion of the circular economy as a new economic hope. A circular economy is one in which products are recycled, repaired or reused rather than thrown away, and in which waste from one process becomes an input into other processes. Reuse means that the product produced by the producer should not be disposable, but it can be used repeatedly in order to save resource consumption and protect the ecological environment. The process of recycle is the core requirement of the circular economy. The waste generated in the production process can also be returned to the production process or by a chemical reaction conversion for other materials and make use of them. The circular economy may best be realized at the city level where cities and their metropolitan regions are at just the right scale to make the shift. This optimistic scenario depends only for the overall commitment of the whole community, states, organizations, companies, individuals. Will you be aware enough, brave and determined enough time will tell? And time is running out, so initiatives need to be bold now.

To implement this kind of "friendly" economic system, it is important to know that first need to make substantial changes to affect change in mental attitudes of individuals, companies and governments, good to "prepare the ground" for to start operating a circular economy in different sectors and in all countries. Only such coordinated and planned concepts form the basis of a sound and effective environmental policy, with sufficient resources and for the survival of the planet Earth.

This optimistic scenario depends only for the overall commitment of the whole community, states, organizations, companies, individuals. Will you be aware enough, brave and determined enough time will tell? And time is running out, so initiatives need to be bold now. 


\section{References}

1. Stahel R.W., 2010: The Performance Economy. Hampshire: New York, Palgrave Macmillan, 2010.p.3.

2. Buren V.N. et all. (2016). Towards a circular economy: the role of Dutch logistics industries and governments. Sustainability 2016, 8, 647; p.1. doi:10.3390/su8070647

3. OECD (2011): The economic significance of natural resources: key points for reformers in eastern Europe, Caucasus and Central Asia. OECD, 2011.p.5.

4. Moula E.M., Sorvari J., Oinas P: Constructing a green circular society. Helsinki: Faculty of social sciences, University of Helsinki, 2017. p. 1.

5. Srisruthi M.K.(2017): Circular economy. International Journal of trend in scientific research and development (IJTSRD). Vol.1, issue 6.p.567

6. Baars M.K.: Circulating the circular economy: To what extent can EU policy incentivise circular economy business models in the plastics industry? ESEI International Business School Barcelona. 2020, p.9.

7. The National Intelligence Council (2013): Natural Resources in 2020, 2030, and 2040: Implications for the United States. 2013. p.iii

8. Christian aid (2012): The rich, the poor and the future of the earth: equity in a constrained world. Christian Aid. 2012. p.2.

https://reliefweb.int/sites/reliefweb.int/files/resources/constrained-world.pdf [accessed 26.02.2021]

9. Lacy, P.; Keeble, J.; McNamara, R.; Rutqvist, J.; Haglund, T.; Cui, M.; Cooper, A.; Pettersson, C.; Kevin, E.; Buddemeier, P.; et al. Circular Advantage: Innovative Business Models and Technologies to Create Value in a World without Limits to Growth; Accenture: Chicago, IL, USA, 2014. p.4.

10. Đoković E., Šećibović R.(2004): Ekonomska geografija sveta. Beograd: Ekonomski fakultet u Beogradu, 2004. str. 33.

11. Hussen M.A. Principles of environmental economics: economics, ecology and public policy. London\&New York: Routledge, 2000.XXV-XXVI.

12. Higgs K. (2017): Limits to growth: human economy and planetary boundaries. The Journal of Population and Sustainability. Vol. 2, No. 1, (Autumn 2017), p.21.

13. EEA Report No 26/2019: Resource efficiency and the circular economy in Europe 2019 - even more from less. An overview of the policies approaches and targets of 32 European countries. p.11 https://www.eea.europa.eu/publications/even-more-from-less. [accessed. 19.02.2021]

14. European Parliament (2017): Towards a circular economy - waste management in the EU. Brussels: European Union: EPRS, 2017. p.1.

15. Australian academy of science (2019): Circular Economy: Redesigning the Future. Australian academy of science (2019). p.5.

16. World Economic forum (2014): Towards the Circular Economy: Accelerating the scale-up across global supply chains. Prepared in collaboration with the Ellen MacArthur Foundation and McKinsey \& Company, WEF, January 2014. p.13.

17. Manniche J et all. (2017): Destination: A circular tourism economy. Centre for Regional \& Tourism Research, 2017. p.6.

18. Westerlo B.V.D.(2011): Sustainable development and the cradle to cradle approach a literature study of the opportunities to apply the Cradle to Cradle approach in the built environment.

Enschede: University of Twente, 2011, p.23

19. Graedel, T.E. \&Allenby, B.R. (1995). Industrial Ecology. New Jersey, Prentice Hall. p.11. https://core.ac.uk/download/pdf/81571617.pdf

20. Cardoso, J. L. (2018). "The circular economy: historical grounds". In Changing Societies: Legacies and Challenges. Vol. iii. The Diverse Worlds of Sustainability, eds. A. Delicado, N. Domingos and L. de Sousa. Lisbon: Imprensa de Ciências Sociais, 118. https://doi.org/10.31447/ics9789726715054.04

21. Heijden van der R., Coenen J., Riel V.A.: Transitioning from a linear economy towards a circular economy: the case of the apparel industry. in Constructing a green circular society. Helsinki: Faculty of social sciences, University of Helsinki, 2017. p.16. 
22. European Commission (2014c). Communication from the Commission to the European Parliament, the Council, the European Economic and Social Committee and the Committee of the Regions. Towards a circular economy: A zero waste programme for Europe. COM(2014) 398 https://ec.europa.eu/environment/circular-economy/pdf/circular-economy-communication.pdf [accessed 25.02.2021]

23. PWC (2018): Closing the loop - the circular economy, what it means and what it can do for you. PwC, 2018. p.5.

24. Wautelet T. (2018): The Concept of Circular Economy: its Origins and its Evolution. 2018. p.1011. https://www.researchgate.net/publication/322555840

25. Stahel, W. R. (2010) The performance economy, 2nd edn, Basingstoke, Palgrave Macmillan. 2010, p.6-7.

26. European Commission. Circular economy: closing loop - an EU action plan for the circular economy. 2016. p.13.

27. OEBS: Cirkularna ekonomija kao sansa za razvoj Srbije. p.11 https://www.osce.org/files/f/documents/a/5/292311.PDF [accesse 02.03.2021]

28. EUMICON (2018): Raw Materials charter 2018. Vienna: European Mineral Resources Confederation, 2018. p.9.

29. Haigh L et all. (2021): The Circulation gap report. Amsterdam: Adessium Foundation, 2021. p.8. https://drive.google.com/file/d/1MP7EhRU-N8n1S3zpzqlshNWxqFR2hznd/edit [accessed 24.02.2021]

30. European Commission (2012: European resource efficiency platform (EREP): Manifesto \& Policy Recommendations. Brussels, adopted 17 December 2012. p.4.

31. Pearce D.W. 2000. Public Policy and Natural Resource Management: A Framework for Integrating Concepts and Methodologies for Policy Evaluation, Report to DGXI, European Commission, Brussels. p.33.

Also available at https://ec.europa.eu/environment/enveco/resource_efficiency/pdf/studies/rmpearce.pdf [accessed 05.03.2021]

32. Dhawan P., Beckmann J. (2018): Circular Economy Guidebook for Cities. CSCP, 2018.p.4.

33. "China to promote circular economy," China Daily, December 2, 2013 (http://www.chinadaily.com.cn/bizchina/greenchina/2013-12/02/content_17144815.htm) [accessed 24.02.2021]

34. World Economic forum (2014): Towards the Circular Economy: Accelerating the scale-up across global supply chains. Prepared in collaboration with the Ellen MacArthur Foundation and McKinsey \& Company WEF, January 2014. p.5.

35. Fogarassy C., Finger D.(2020). Theoretical and Practical Approaches of Circular Economy for Business Models and Technological Solutions. Resources 2020, p.3-4.; doi:10.3390/resources9060076

36. Mazza L., Brink T.P.: Green Economy Supporting briefing green economy in the European Union. UNEP, 2012. p.9.

37. Higgs K(2017): Limits to growth: human economy and planetary boundaries. Vol.2, no.1 (2017).p31.

38. Ellen Macarthur Foundation (2020): How policymakers can achieve a resilient recovery with the circular economy.p.2-3. www.ellenmacarthurfoundation.org [accessed: 17.04.2021] 